\title{
SOCIALLY RESPONSIBLE INVESTING TOWARDS IMPACT INVESTMENTS: RECENT DEVELOPMENTS IN SOCIAL FINANCE
}

\author{
DOI: 10.17261/Pressacademia.2018.1005 \\ JEFA- V.5-ISS.4-2018(7)-p.385-394
}

Narman Kuzucu

Beykent University, Faculty of Economics and Administrative Sciences, Department of Business, Ayazaga-Maslak Campus, Istanbul, Turkey. narmankuzucu@beykent.edu.tr, ORCID: 0000-0003-2265-6492

Date Received: September 16, $2018 \quad$ Date Accepted: December 23, 2018

To cite this document

Kuzucu, N. (2018). Socially responsible investing towards impact investments: recent developments in social finance. Journal of Economics, Finance and Accounting (JEFA), V.5(4), p.385-394.

Permanent link to this document: http://doi.org/10.17261/Pressacademia.2018.1005

Copyright: Published by PressAcademia and limited licenced re-use rights only.

\begin{abstract}
Purpose - Socially responsible finance has emerged as a growing area of interest. In this study, the objective is to define the conceptual framework of socially responsible investing and impact investments and to discuss the recent approaches which have become prominent. Methodology - We discussed the current literature by reviewing published academic studies and practitioners' reports.

Findings- We determined that various non-governmental organizations and international organizations endeavored to promote the development of socially responsible investing globally. While the conceptual framework has been growing recently, measuring social impact has been the area in which the most important developments have been seen.

Conclusion- A perception, that prioritizes social impact, sustainability and corporate governance rather than individual benefit, has been advancing theoretically and practically. Concordantly, new approaches should be designed; new financial instruments, which address various social needs, should be innovated. Moreover, new regulations should be adopted. It is promising that a financial model, which pursues the whole society's benefit and cares about sustainability issues such as environment, is progressing.
\end{abstract}

Keywords: ESG criteria, impact investments, social finance, socially responsible investing

JEL Codes: G11, G38, G39

\section{SOSYAL SORUMLU YATIRIMDAN ETKI YATIRIMLARINA: SOSYAL FINANSTA GÜNCEL GELIŞMELER}

\section{ÖZET}

Amaç- Sosyal sorumlu finans, gittikçe büyüyen bir ilginin olduğu alan olarak karşımıza çıkmaktadır. Bu çalışmada, halen hızlı bir gelişim içerisinde olan sosyal sorumlu yatırımlar ve etki yatırımlarının kavramsal çerçevesini ortaya koymak, bu alanlarda öne çıkan güncel yaklaşımları tartışmak amaçlanmıştır.

Yöntem- Güncel bir literatür taraması yapılarak, ilgili alanda yayınlanmış akademik çalışmalar ve uygulamacı raporları incelenmiştir.

Bulgular- Sosyal sorumlu yatırımların gelişimine öncülük etmek için pek çok sivil kuruluşla birlikte, çeşitli uluslararası örgütlerin küresel düzeyde çalışmalar yaptığı belirlenmiştir. Yakın zamanda kavramsal çerçeve gelişirken, en çok gelişmelerin olduğu alan, sosyal etkinin ölçülmesi metodolojisi olmuştur.

Sonuç- Bireysel faydadan ziyade, toplumsal etki, sürdürülebilirlik ve kurumsal yönetişimi önceleyen bir finansal anlayışın hem teorik alanda hem de uygulamada gelişmekte olduğu görülmektedir. Buna paralel olarak, farklı sosyal ihtiyaçlara hitap eden yeni yaklaşımların ve yeni finansal araçların tasarlanmasına, düzenlemelerin geliştirilmesine ihtiyaç vardır. Tüm toplumun faydasını gözeten, çevre gibi sürdürülebilirlik konularında duyarlılık gösteren bir finans ve yatırım modelinin gelişmesi gelecek vadetmektedir.

Anahtar Kelimeler: ÇSY kriterleri, etki yatırımları, sosyal sorumlu finans, sosyal sorumlu yatırım JEL Kodları: G11, G38, G39

\section{Giriş}

Sosyal sorumlu finans, gittikçe büyüyen bir ilginin olduğu alan olarak karşımıza çıkmaktadır. Bu çalışmada, teoride ve pratik alanda gelişmekte olan sosyal finans alanında öne çıkan sorumlu finans, etki yatırımları, çevresel, sosyal ve yönetişim 
kriterleri gibi konuların ayrımını yapmak, söz konusu alanlara ilişkin akademik literatür ve pratisyen raporlarını tarayarak yakın zamanda ortaya çıkan ve gelişen yaklaşımları araştırmak amaçlanmıştır. Bu amaçla, güncel bir literatür taraması yapılarak, ilgili alanda yayınlanmış akademik çalışmalar ile uygulamacı ve araştırmacı kurum raporları incelenmiştir.

Yakın zamanda ivme kazanarak gelişimini hızlandıran alanda küresel terminoloji İngilizce olduğundan, bu çalışmada kavramların İngilizce orijinallerine ve çoğu zaman tarafımızca getirilen Türkçe karşılıklarına beraberce yer verilmiştir. Genel olarak "sosyal sorumlu finans" (SSF) olarak adlandırılan ve gelişmekte olan finans alanı birbirine yakın anlamda pek çok adlarla anılmaktadır. Bunların öne çıkanlarını yaygın olarak kullanılan İngilizce terimler ile Türkçe karşılıklarını şöyle sıralayabiliriz:

- $\quad$ social finance / sosyal finans,

- (socially) responsible investments / (sosyal) sorumlu yatırımlar,

- ethical investing / etik yatırımlar,

- green investing / yeşil yatırımlar,

- (social) impact investments / (sosyal) etki yatırımları.

Bu kavramların yanı sıra mikro finans, sosyal bankacılık, kitle fonlaması, sosyal işletmecilik, sosyal girişimcilik, çevresel, sosyal ve yönetişimsel kriterler gibi kavramlar sosyal finans ile yakından ilişkilidir.

Çalışmamızın takip eden ikinci bölümünde sosyal sorumlu yatırımların ortaya çıkışına ve tarihsel süreçte gelişimine kısaca yer verilmiştir. Üçüncü bölümde, sosyal sorumlu yatırımın tanımı ve kapsamı tartışılmıştır. Bu çerçevede sosyal sorumlu yatııım kavramının evrimine, çevresel, sosyal ve yönetişimsel kriterlere uygun yatırımlar, etki yatırımları gibi sorumlu yatırım türleri ile özet olarak sorumlu yatırım pazarı ve finansal araçlara değinilmiştir. Dördüncü bölümde ise sosyal etkinin ölçülmesi ve bu alanda yakın zamanda geliştirilen metodolojiler ele alınmıştır. Son bölümde, çalışmada elde edilen bulguların genel bir değerlendirmesi yapılmıştır.

\section{SOSYAL SORUMLU YATIRIMIN TARIHSEL GELIŞIMI}

Sosyal sorumlu yatırımın (SSY) kökenleri, orta çağa kadar götürülebilmektedir. Avrupa'da 15. yüzyılda, Franciscan hareketi tarafından İtalya'da kurulan ve mensuplarına finansal destekler sağlayan Monti di Pietà, örnek olarak gösterilebilir. Daha sonraki zamanlarda kredi birliklerinin ve kooperatif bankalarının da benzer işlevleri olduğu, dezavantajlı kesimlere ve üyelerine finansal hizmetler sunmak için kuruldukları bilinmektedir (Chiappini, 2017, s.20).

Amerika'da ise SSY'nin ilk örnekleri, 18. yüzyılda bazı dini grupların, bağış fonlarının köle ticaretinde kullanılmasına karşı çıktığı sömürge döneminde görülmektedir. 1960 ve 70'lerde ise sorumlu yatırım anlayışının dini çerçeveden çıkıp, Vietnam Savaşı ve Güney Afrika'daki ırk ayrımcılığı gibi sosyal ve siyasal olayların da etkisiyle, daha protest bir çerçevede, toplumsal amaçlara yönelik bir yatırım şekli olduğunu görmekteyiz (Commonfund Institute, 2013).

Birleşmiş Milletler, 2006 yılında "çevresel, sosyal ve yönetişimsel” (ÇSY) kriterler ile yatırım performansının ilişkisini formüle ederek, yatırımcıların gönüllü olarak uyulabileceği Sorumlu Yatııım ilkelerini (Principles for Responsible Investment / UN PRI) yayınlamıştır. Birleşmiş Milletler Sorumlu Yatırım illkeleri, yatııımcıların edilgen bir tutumla, zayıf ÇSY kayıtlarına sahip şirketlere yatırım yapmasını önlemekten daha çok, yatırım yapılacak şirket veya varlıkların çSY öğelerinin yatırım performansına katkısı ölçüsünde değerlendirilmesini önermektedir. Buna göre, ÇSY kriterlerinin yatırımların seçimi sürecindeki etkisi dinamik olmalıdır. ÇSY kriterleri dikkate alınırken, aynı zamanda farklı şirketler, sektörler, bölgeler incelenerek geleneksel yatırım analizi esaslarına uygun olarak değerlendirme yapılmalıdır (Commonfund Institute, 2013; UN PRI, 2016).

Birleşmiş Milletler tarafından Sorumlu Yatırım İlkelerinin yayınlanmasıyla, çsY kriterlerinin çerçevesi belirlenmiştir. 2013 yılına gelindiğinde pek çok finans kurumu ÇSY kriterlerini entegre ederek, sadece Avrupa Birliği'nde 1,9 trilyon Euro'nun üzerinde fonu yönetiyordu. 2015 yılı itibariyle bu rakam, iki yılda toplam \% 40'a yakın bir büyümeyle 2,6 trilyon Euro'nun üzerine çıkmıştır (Eurosif, 2016).

2013 yılında, İngiltere'nin başkanlığındaki G8 zirvesinde kurulan Sosyal Etki Yatırım Özel Görev Komitesi (SIIT) tarafından sosyal etki yatırımlarının geliştirilmesi amacıyla çalışmalar yürütüldü. Bu çalışmaların sonucu olarak, 2014 yılında bir dizi tavsiye raporları yayınlandı (SIIT, 2014a, 2014b, 2014c).

Günümüzde sosyal sorumlu yatırım yapan ya da özellikle bu alana odaklanmış pek çok kurum ve bu kurumların oluşturduğu ağlar bulunmaktadır. Bunların en önemlilerinden olan Küresel Etki Yatırım Ağı (Global Impact Investing Network / GIIN), sosyal sorumlu yatırımların büyüklüğünün ve etkinliğinin artırılmasına küresel olarak öncülük eden kar amaçlı olmayan bir kuruluştur. Kuruluş, vizyonunu şu şekilde açıklamaktadır: "Vizyonumuz, finansal pazarların toplumun tüm üyelerine hizmet ettiği ve finansın küresel toplumun sosyal ve çevresel meselelerinin çözülmesinde merkezî rol oynadığı bir dünyaya dairdir. 
Böyle bir gelecekte yatırımcılar; güçlü toplumlar, sağlıklı bir çevre ve bütün insanlar için sürdürülebilir bir gelecek inşası için, tüm kararlarında "etki" değerlendirmesinde bulunurlar" (GIIN, 2018).

\section{SOSYAL SORUMLU YATIRIMIN TANIMI VE KAPSAMI}

SSF, finans yoluyla pozitif sosyal etki yaratmaya çalışır. Pozitif sosyal etki ise yatırımın toplum, çevre ve sürdürülebilir kalkınma üzerindeki etkisidir. Söz konusu etki; krediler, yatırımlar, mikrofinans gibi hizmetler ve finansal ürünlerle oluşturulmaya çalışılır (Weber \& Duan, 2012, s.161). SSY, finansal getiri elde etmek ve aynı zamanda pozitif sosyal etki yaratmak için ÇSY kriterlerini kullanırlar (US SIF, 2016).

SSY, kişisel değerler ve toplumsal kaygıları, yatırım kararlarıyla bütünleştirir. Bu amaçla yatırımcılar; yatırım alternatiflerini, faaliyetleri veya ürünleri sosyal sorumluluk ölçülerine uygun olan işletme ve şirketlerle sınırlandırırlar (Baker \& Nofsinger, 2012, s.3; Bollen, 2007). Sosyal finansın finansal kaynak sağladığı alanların başlıcaları özetle şunlardır; fakirlik ve açıkla mücadele, finansal kaynaklara erişimi sınırlı, dezavantajlı kesimlerin sosyal ihtiyaçlarının karşılanması, çevresel sorunlar ve sosyal girişimcilik.

\subsection{Sosyal Yatırımlarda Kullanılan Belirleme Yöntemi: İzleme}

Sosyal sorumlu yatırımcıların hangi alanlara ya da hangi varlıklara yatırım yapacağını belirleyebilmek amacıyla izleme yapmak gereklidir. İzleme (screening), bireysel ve kurumsal yatırımcıların yatırım alanlarını seçerken bir tür filtreleme ve seçim kıstasları kullanmasını ifade etmektedir. İzleme, iki türlü olabilmektedir. Bunlar, negatif izleme ve pozitif izleme yöntemleridir.

i) Negatif izleme: Sosyal sorumlu yatırımcıların duyarlılık taşıdığı bir takım sosyal, etik veya dini değerlere aykırı alanlara yatırım yapılmamasıdır. Bu alanlarda faaliyet gösteren ya da söz konusu değerlere aykırı hareket eden işletmeler yatırım listesinden çıkarılır. Sağlığa zararlı ya da günah kabul edilen tütün, alkol, kumar gibi alanlarda faaliyeti olan işletmelere yatırım yapılmaması ya da çevreye zehirli atık bırakan, insan hakları ihlallerine karışan firmaların yatırım portföyünden çıkarılması verilebilecek örneklerdir.

ii) Pozitif izleme: ÇSY kriterlerine göre sınıfında en iyi uygulamalara yer veren işletmelere yatırım yapılmasını ifade eder. Örneğin, geri dönüşüm konusunda en iyi uygulamalara yer veren işletmelere yatırım yapılması ya da şeffaflık, paydaş hakları konusunda duyarı işletmelerin yatıım için seçilmesi pozitif izleme yönteminin kullanılmasıdır (Commonfund Institute, 2013; Fullwiler, 2016)

\subsection{Geleneksel Sosyal Sorumlu Yatırımdan ÇSY Yatırımlarına}

Yakın zamanlara kadar terminolojik kullanımda, SSY ile ÇSY kriterlerine uygun yatırım kavramları arasında fark yokmuş gibi görünse de günümüzde, bu iki yatırım şekli arasında bir farklılaşma bulunmaktadır.

SSY, etik değerlere göre yönlendirilen ve negatif izleme içeren yatırımları ifade etmektedir. SSY'da etik değerler ve kriterler sübjektif olduğundan, yatırımcılara göre değişiklik gösterebilmektedir. Ancak ÇSY yatırımlarında odak noktası, yüksek yatırım potansiyeli bulunan şirketlerin sürdürülebilirlik konusundaki performanslarıdır. Buna göre belirli yatırımlar negatif izlemeye alınmamakta, fakat ÇSY kriterleri dikkate alınarak bir sıralama veya derecelendirmeye tabi tutulmaktadırlar. Yatırım kararı verilirken yüksek sıralamalı şirketler öncelikli değerlendirilmektedir. ÇSY kriterleri, SSY ile karşılaştırıldığında evrensel bir yaklaşımı temsil etmektedir (Commonfund Institute, 2018; Drexler and Noble, 2013). O'Donohoe vd. (2010, s.14)'ne göre; SSY, olumsuz etkiyi en aza indirmeyi amaçlayan yatırımlarken, ÇSY yatırımları ise proaktif biçimde olumlu sosyal ve çevresel etkiler yaratır.

Literatürde SSY ve ÇSY yatırımlarının farklı anlamlarda kullanıldığı görülmektedir. SSY, daha genel ve sorumluluk kavramının yatırımcıya göre değiştiği sübjektif bir anlam taşırken, ÇSY yatırımları sorumluluk ölçütlerinin çevresel, sosyal ve yönetişimsel olarak somutlaştırıldığı, bununla birlikte bu alanlarda olumlu bir etki yaratmak için aktif bir tutumun izlendiği yatırım şeklidir. Buna göre, SSY daha çok negatif izleme kullanırken, ÇSY yatırımları pozitif izlemeyi benimsemektedir.

\subsection{Sosyal Etki Yatırımları (Impact Investments)}

Sosyal etki yatırımlarını, SSY ve ÇSY yatırımların yanı sıra ayrı bir sosyal yatırım tanımı olarak sayabiliriz. Etki yatırımları adı, ilk defa İtalya'daki Rockefeller Merkezinde 2007 yılında bir araya gelen, finansal getiriden çok sosyal getiriye odaklanan uygulamacılar tarafından kullanılmıştır (Harji \& Jackson, 2012). Etki yatırımları, sosyal sorumlu yatırımların günümüzde ulaştığı en güncel, aktif ve objektif anlamı ifade etmektedir. Zira meydana getirilen etkinin ölçülerek, performansın belirlenmeye çalışıması sorumlu finansta yeni bir yaklaşımdır. 
O'Donohoe vd.'ne göre (2010), etki yatırımları, finansal getirinin ötesinde pozitif sosyal etki yaratmak amacıyla yapılan yatırımlardır. Buna göre, bu tür yatırımlar, finansal risk ve getiriye ek olarak, sosyal ve çevresel performansın da yönetilmesini gerektirirler (Weber \& Duan, 2012, s.165). Küresel Etki Yatırımı Ağı'nın etki yatırımları tanımı şu şekildedir: Finansal bir getirinin yanı sıra ölçülebilir sosyal ve çevresel etki yaratmak amacıyla çeşitli şirket, kuruluş ve fonlara yapılan yatırımlardır (GIIN, 2018).

Etki yatırımları dört temel karakteristik özelliğe sahiptir:

- İsteklilik: Bir yatırımcının yapılan yatırım yoluyla bir pozitif sosyal veya çevresel etki meydana gelmesi konusunda istekli ve niyetli olması.

- Getiri beklentisi olan yatırım: Etki yatırımlarının az miktarda bile olsa finansal getiri sağlaması beklenir.

- Getiri beklentisine göre farkıı varlık türleri: Etki yatııımları, -piyasanın altındaki bir orandan riske göre düzeltilmiş piyasa oranına kadar- belirli bir düzeyde finansal getiri hedeflerler. Buna göre, yatırım yapılacak varlıklar, finansal getirisi olan varlıklar olmalıdır.

- Etkinin ölçümü: Etki yatırımının ayırıcı özelliği; şeffaflık ve hesap verilebilirliğin sağlanarak, yapılan yatırımların sosyal ve çevresel performansının ve ilerlemesinin ölçülmesi ile raporlanmasının yatırımcının sorumluluğunda olmasıdır (GIIN, 2018).

Höchstädter ve Scheck (2015, s.456), hem akademik çalışmaları hem de uygulamacıların yayınlarını inceleyerek, etki yatıımlarının SSY'nın ötesine geçmiş bir yatırım biçimi olduğunu savunmuşlardır. SSY ve etki yatırımları arasında şu iki unsurun farklılık gösterdiğini belirlemişlerdir.

i) Yatırımın büyüklüğü: SSY, genellikle daha büyük ölçekte kurumlara yatırım yapmayı hedeflerken, etki yatırımları daha küçük ölçekli yatırımları tercih eder.

ii) Yatırımın mahiyeti: Sorumlu yatırımcılar, ikinci el piyasada alınıp satılabilen hisse senedi, tahvil gibi menkul kıymetleri ve fonları kullanırken, etki yatırımcıları doğrudan borç verme ya da özkaynağa katılma (ortak olma) yoluyla kuruluşların finansmanını sağlarlar.

Tablo 1, sorumlu yatıım perspektifinden yatırım yelpazesini göstermektedir. Söz konusu sınıflandırma ve tanımlama modeli, Ingiltere'nin başkanlığında G-8 zirvesinde kurulan Sosyal Etki Yatırımları Özel Görev Komitesince 2014 yılında hazırlanmış ve daha sonra bu alanda yapılan pek çok çalışmada referans alınmıştır (SIIT, 2014a, 2014b; Wilson vd., 2015). Model, yatırımları sosyal sorumluluk penceresinden ya da diğer bir deyişle sosyal etkileri bakımından beş gruba ayırmaktadır. Bu beş grubun bir ucunda sadece mali getiri elde etmek için yapılan yatırımlar bulunurken, diğer bir ucunda sadece sosyal etki yaratmak amacıyla yapılan sermaye harcamaları vardır. Arasında kalan üç grup ise sosyal sorumluluk düzeylerine göre Sorumlu, Sürdürülebilir ve Etki Yatııımları olarak sıralanmaktadır. Sadece mali yatırımlardan, sadece etki yatırımlarına doğru ilerlerken finansal getiri oranları düşmekte, buna mukabil çSY riskleri azaltılmaktadır. Söz konusu şemada, genel karakteristiği "ölçülebilir yüksek etkili çözümlere odaklanma" olarak belirtilen etki yatırımları da finansal getirilerine göre üç gruba ayrıııştır. Örnek vermek gerekirse, geleneksel kar amaçlı yatırımlar sadece mali yatırımlar sınıfına girerken, vakıf ya da benzer kurumların hiçbir finansal getiri beklemeden yaptıkları sosyal amaçıı harcamaları sadece etki sınıfına girmektedir. 
Tablo 1: Sosyal Sorumluluk Perspektifinden Yatırım Yelpazesi

\begin{tabular}{|c|c|c|c|c|c|c|}
\hline Sadece malî & Sorumlu & Sürdürülebilir & \multicolumn{3}{|c|}{ Etki } & Sadece etki \\
\hline \multicolumn{4}{|c|}{ Rekabetçi malî getiri elde edilmesi } & & & \\
\hline \multicolumn{6}{|c|}{ Çevresel, Sosyal ve Yönetişimsel risklerin azaltılması } & \\
\hline & & \multicolumn{3}{|c|}{ Çevresel, Sosyal ve Yönetişimsel fırsatların gözetilmesi } & & \\
\hline & & & \multicolumn{3}{|c|}{ Ölçülebilir yüksek etkili çözümlere odaklanma } & \\
\hline & & & \multicolumn{2}{|c|}{ Rekabetçi mali getiriler } & & \\
\hline $\begin{array}{l}\text { Çevresel, sosyal ve } \\
\text { yönetişimsel } \\
\text { uygulamaların sınırlı } \\
\text { düzeyde olması } \\
\text { veya hiç olmaması }\end{array}$ & $\begin{array}{l}\text { Riskli çevresel, sosyal ve } \\
\text { yönetişimsel uygulamaları } \\
\text { hafifleterek değerin } \\
\text { korunmasını sağlar. }\end{array}$ & $\begin{array}{l}\text { Değer güçlendirecek, } \\
\text { geliştirici çevresel, } \\
\text { sosyal ve yönetişimsel } \\
\text { uygulamalar benimser. }\end{array}$ & $\begin{array}{l}\text { Sosyal sorunlara hitap } \\
\text { ederken yatırımcılara } \\
\text { rekabetçi mali getiri } \\
\text { sağlar. }\end{array}$ & $\begin{array}{l}\text { Sosyal sorunlara hitap } \\
\text { ederken, yatıımcılara } \\
\text { piyasanın altında mali } \\
\text { getiri sağlar. }\end{array}$ & $\begin{array}{l}\text { Sosyal sorunlara hitap } \\
\text { ederken, yatırımcılara } \\
\text { piyasanın altında mali } \\
\text { getiri gerektirir. }\end{array}$ & $\begin{array}{l}\text { Yatırımcılara mali getiri } \\
\text { sağlamadan sosyal } \\
\text { sorunlara hitap eder. }\end{array}$ \\
\hline
\end{tabular}

Kaynak: İngiltere'nin başkanlığındaki 2013 yılı G8 zirvesinde kurulan Sosyal Etki Yatııı Özel Görev Komitesi (2014) tarafından hazırlanan “Allocating for Impact” adlı rapordan alınmıştır (SIIT, 2014a). 


\subsection{Sosyal Sorumlu Yatırım Pazarı ve Araçları}

Sosyal sorumlu yatırım pazarı her geçen yıl büyümekte ve yeni araç geliştirmeleri devam etmektedir. Son on yıldaki yıllık ortalama büyüme \%18 gibi dikkat çekici bir orandır. Varlıkların toplam büyüklüğü, 2016 başı itibariyle yaklaşık 23 trilyon USD olduğu kaydedilmektedir. Söz konusu varlıkların \%58'i Avrupa, \%38'i ABD’de bulunmaktadır (US SIF, 2017).

SSF pazarını talep ve arz tarafıı olmak üzere iki taraflı olarak inceleyebiliriz.

Talep tarafı: Sosyal mallar ve hizmetlere olan ihtiyaçları karşılanamayan sosyal kesimler ile bu kesime hizmet sunmak, ihtiyaçlarını karşılamak amacıyla finansal kaynaklar talep eden kuruluşlar oluştururlar. (Örnek: Mikro finans kurumları, sosyal bankalar, kooperatifler, sosyal girişimciler, vs.)

Arz tarafı: Arz tarafının varlık sahipleri ile varlık yöneticileri oluşturur. Varlık sahipleri; bireysel yatırımcılar, şirketler, vakıf, dernekler, kamu idareleri gibi ellerinde bulunan varlıklarla sosyal etki yaratma isteğinde olan taraflardır. Varlık yöneticileri ise fon yöneticileri, emeklilik fonları, bankalar, kalkınma finansman örgütleri, kamu yatırım programları gibi ellerinde bulunan veya topladıkları varlıklara sosyal amaçlarla birlikte kâr güdüsüyle yön veren şahıs ve kurumlardır (SIIT, 2014a).

Sosyal sorumlu yatırım varlıkların büyük bir kısmını emeklilik fonları, yatırım fonları gibi sosyal sorumlu özel fonlar oluşturmaktadır. Bunların yanı sıra, henüz çok fazla rakamlara ulaşmamış olan yenilikçi bir araç olan sosyal etki tahvilleri dikkat çekmektedir. Sosyal etki tahvilleri ya da ABD'deki adıyla "başarı için ödeme" tahvilleri (pay for success bonds) sabit getirili bir yatırım aracı olmakla birlikte, yatırımcının da sosyal riskleri üstlendiği bir tür yapılandırılmış finans ürünleridir. Bunlar da kalkınma etki tahvilleri (DIB) ve çevresel etki tahvilleri (EIB) olmak üzere iki çeşittir (Chiappini, 2017, s.34-35; Drexler \& Noble, 2013; Wilson vd., 2015).

İlk sosyal etki tahvili, 2010 yılında İngiltere'de Adalet Bakanlığı tarafından 5 milyon Sterlin tutarında çıkarıldı. Söz konusu tahvilin amacı, mahkumların yeniden suç işleme oranını azaltmak ve onları topluma entegre etmek idi (Schinckus, 2018). Amerika'da ise Washington DC Su ve Kanalizasyon Idaresi, 2016 Eylülünde Goldman Sachs and Calvert Foundation işbirliğiyle çevresel etki tahvili 25 milyon USD tutarında ihraç etti. Bu ihraçta, sel taşkınlarından kaynaklanabilecek riskler, yatırımcılar ve İdare tarafından beraberce üstlenildi (Chiappini, 2017, s.34-35).

Illk sosyal hisse senedi borsası, Londra'da 2013 yılında Sosyal Hisse Senedi Borsası (Social Stock Exchange / SSX) adı altında kuruldu. Söz konusu borsanın lisanslı işletmecisi, İngiltere'nin önemli etki yatırım aktörlerinden olan Etki Yatırım Ağı (Impact Investment Network) adlı kuruluştur. Anılan borsada, 2018 yılı itibariyle 50 kadar şirket işlem görmektedir. Bir diğer sosyal borsa, özellikle kadının toplumda güçlendirilmesi ve dezavantajlı topluluklara hizmet edilmesi konularında faaliyetleriyle öne çıkan, Singapur orijinli Impact Investment Asia (Asia IIX) adlı etki yatırımı kurumu ve Morityus Borsası tarafından Morityus'da kuruldu (Chiappini, 2017, s.28; Drexler \& Noble, 2013).

Mikro krediler, özellikle fakirlikle mücadele ve dezavantajı sosyal grupların kalkınması amacıyla uzun yıllardır kullanılagelen bir yöntemdir. Ayrıca demokrasi ve insan haklarının geliştirilmesi, kadının toplumsal statüsünün yükseltilmesi gibi amaçlara da hizmet etmektedir. Bu gibi amaçlarla özellikle gelişmekte olan ülkelerde mikro finans kuruluşları kurularak, hitap edilen soruna göre finansal kaynaklara erişimi olmayan kişilere uygun faizlerde küçük ölçekte krediler verilmektedir. Bu kurumlar sayesinde sosyal piramidin en altında bulunan kesimler, kendi işlerini kurarak hayatlarını sürdürebilecek imkanlara kavuşmaktadır (Weber \& Duan, 2012, s.172).

Sosyal sorumlu yatırımlarda kullanılan yenilikçi araçlardan bir diğeri de kitle fonlamasıdır. Kitle fonlaması (crowdfunding), bir proje veya girişimin finansmanını sağlamak üzere geniş bir kitleden küçük miktarlarda para toplamak anlamına gelmektedir. Özellikle sosyal girişimlerin finansmanında ve yenilikçi fikirlerin hayata geçirilmesinde başvurulan bir finansman yöntemidir. Küçük miktarda katılımda bulunan fon sağlayıcıların bir teminat ya da iş planı talep etmemesi, fon ihtiyacında olan girişimciler için avantaj sağlar. Kitle fonlaması, borç kitle fonlaması, özkaynak kitle fonlaması olmak üzere iki farklı şekilde yapılabilmektedir. Yaygın olarak internet ve sosyal medya platformları kullanılmaktadır (Lehner, 2016).

\subsection{Mevzuat Düzenleme îhtiyacı}

Çalışmamızın odağında olmamakla birlikte, sosyal sorumlu yatırım piyasaları ve yatırım araçlarına yönelik yasal düzenlemeler hakkında kısa bir bilgilendirme yapmak uygun olacaktır. Yeni yatırım araçlarının ve yöntemlerinin geliştirildiği sosyal finans alanında yasal düzenlemeler yapılması kaçınılmazdır. Bazı ülkelerin bu alanda sınırlı da olsa belirli finansal araçlar için düzenlemeler yaptığı görülmektedir. Örneğin, İtalya mikro kredi uygulamaları için 2010 yılında yasal mevzuat hazırlamıştır. Nispeten yeni bir yöntem olan kitle fonlaması için de pek çok ülke düzenleme yapma imkanlarını aramaktadır (Addis, 2015).

ABD'de emeklilik fonları için konvansiyonel yatırım fonlarının yanı sıra, katılımcılara sosyal sorumlu alternatifler sunulmaktadır. Böylece bireysel yatırımcılara tasarruf ve emeklilik birikimlerini sosyal sorumlu yatırım fonlarında değerlendirme imkanı verilmektedir (Chiappini, 2017, s.29). Bunu, Türkiye'deki bireysel emeklilik sistemindeki bireysel 
yatırımcılara sağlanan faizsiz katılım bankacılığı alternatifine benzetmek mümkündür. İskandinav ülkelerinde de yaygın olan sosyal sorumlu emeklilik fonlarıyla bireysel yatırımcı, emeklilik planı kapsamında tasarruf yaparken, aynı zamanda topluma değer katma imkanı bulabilmektedir.

Sosyal Etki Yatırım Özel Görev Komitesi, sosyal ve çevresel amaçları olan etki yatırımları için, hükümetlere bu tür yatırımlar önündeki potansiyel engellerin kaldırılması ve kolaylaştırılması için önerilerde bulundu (SIIT, 2014b).

ABD'de "B Lab" adında kar amaçlı olmayan bir kuruluş, 'fayda şirketi' (benefit corporation veya kısaca B Corp) adıyla yeni bir şirket türünün yasal olarak kabul edilmesi konusunda çaba göstermektedir. ABD eyaletlerinin büyük bir kısmı bir takım farklılıklarla söz konusu öneriyi kabul etmiştir. Sorumluluk ve faaliyet alanı sosyal etki yatırımları olması öngörülen ve bu alanda şeffaflık ve hesap verilebilirliği artırması amaçlanan 'fayda şirketi', İtalya ve Avustralya yasal mevzuatına da girmiştir (B Lab, 2018; Chiappini, 2017, s.29-30).

\section{SOSYAL ETKININ ÖLÇÜLMESi}

Sosyal sorumlu yatırımlarda ve etki yatırımlarında belirli bir düzeyde kar elde etmekle birlikte sosyal etki oluşturulması amaçlanmaktadır. Elde edilen getiri, geleneksel finansal ölçüm yöntemleriyle hesaplanmaktadır. Ancak meydana getirilen sosyal etkinin ölçülmesi yatırımın etki performansını belirlemek bakımından önem arz etmektedir. Bu nedenle, farklı kuruluşlar ve gruplar tarafından, yeni yeni teknikler ve ölçüm yöntemleri geliştirilmektedir. Bu bölümde, halen geliştirilmekte olan sosyal etki ölçüm yöntemlerine kısaca yer verilecektir.

Sosyal etkinin ölçülmesine yönelik önerilerde bulunan SIIT çalışma grubu, sosyal etkinin ölçülmesinde 7 aşama belirlemiştir: Ölçüm hedeflerinin belirlenmesi, bir ölçüm çerçevesinin tasarımı ve göstergelerin seçimi, veri toplama ve saklama, geçerleme, veri analizi, sonuçların raporlanması ve son olarak sürecin geliştirilmesi (SIIT, 2014c). Farklı ölçüm yöntemlerinin öneriyi dikkate alarak anılan aşamalara benzer uygulamalara yer verdiği görülmektedir.

\subsection{Yatırımın Sosyal Getirisi (SROI / Social Return on Invesment) Analizi}

Yatırımın sosyal getirisi, yatırım getirisi (ROI) oranıyla benzerlik taşımaktadır. Bu oranın paydasında ROI'da olduğu gibi yatırım yapılan parasal tutar yer alırken, payında elde edilen sosyal, çevresel sonuçların parayla temsil edilen getirisi bulunmaktadır. Böylece ne kadarlık bir maliyetle ne kadarlık bir fayda sağlandığı ölçülmeye çalışılmaktadır. Bu bakımdan fayda maliyet analiziyle de benzerliği bulunmaktadır. SROI, parasal bir ölçüm olsa da paranın değil, değerin ölçüldüğü bir yöntemdir.

SROI analizinin fayda maliyet analizinden temel farkı, SROI analizi farklı paydaşların perspektifinden değer ölçümü yaparken, fayda-maliyet analizi tüm toplumun faydasını makro perspektif ile değerlendirir. Ortak özellik ise, maliyet ve faydayı ikisinin de parasal olarak ölçmeye çalışmasıdır (SROI Network, 2012, s. 96)

Yatırımın sosyal getirisi oranı iki türlü olabilmektedir: i) Değerlendirmeye yönelik ve ii) tahminî. Birincisinde geçmişe yönelik olarak, yapılmış bir yatırımın sosyal getirisi ölçülmeye çalışılırken, ikincisinde planlanan yatırımın arzu edilen sonuçlarına ulaşıldığında ne kadarlık bir sosyal değer yaratılacağı ölçülmektedir (SROI Network, 2012, s. 8).

SROI ölçümünün yapılmasında karşılaşılan en büyük sorun yatırımın sonuçlarına dair yeterli düzeyde veri bulunamamasıdır. Bu sorunun aşılabilmesi için SROI analizi yaparken, değerlendirmeye yönelik değil, tahminî SROI analizinin ilk olarak yapılması önerilmektedir. Böylece ölçümde kullanılacak sonuçlara ilişkin verilerin toplanması için gerekli sistemi önceden kurmak mümkün olabilecektir. (SROI Network, 2012, s. 8-9)

SROI, yapılan yatırımların finansal getirisini değil, sosyal getirisini dikkate alır. SROI analizi 6 aşamada gerçekleşir:

1. Kapsamın ve önemli paydaşların belirlenmesi: SROI analizinin neleri kapsayacağını ve sınırlarını bilmek, süreçte kimlerin, nasıl rol alacağını açıkça belirlemek önemlidir.

2. Ortaya çıkacak sonuçların haritalanması: Paydaşlarla ilişkiler kurulması esnasında girdiler, çıktılar ve sonuçlar arasındaki ilişkiyi gösteren bir etki haritası geliştirilmelidir.

3. Sonuçların elde edilip edilmediğinin belirlenmesi ve bir değer atfedilmesi: Sonuçların gerçekleşip gerçekleşmediğine dair verilerin toplanması ve bunların değerlenmesi aşamasıdır.

4. Etkinin belirlenmesi: Sonuçlara dair kanıtların toplanması ve bunların parasal değerlerinin belirlenmesinden sonra, ortaya çıkan değişimin dikkate alınmayan başka faktörlerin sonucu mu olduğu belirlenmelidir.

5. SROI'nin hesaplanması: Bu aşamada elde edilen tüm faydalar toplanırken, olumsuzluklar çıkarılarak sonuç, yapılan yatırımla karşılaştırılır. Sonuçların duyarlıı̆̆ı da bu aşamada test edilebilir.

6. Raporlama ve bulguların paylaşılması: İhmal edilebilen ancak hayati önemi haiz son aşamada, bulgular paydaşlarla paylaşılır ve onların sorularına cevaplar verilir. 
SROI analizinin 7 ilkesi vardır: Paydaşları dahil et. / Neyin değiştiğini anla. / Fark yaratacak şeyleri değerle. / Sadece önemli olan şeyleri dahil et. / Abartma. / Şeffaf ol. / Sonuçları doğrula (SROI Network, 2012). Sayılan ilkeleri kısaca hesap verilebilirlik, şeffaflık, önemlilik, objektiflik, açıklık ve doğruluk kavramlarıyla özetlemek mümkündür. Toplanılan verilerin parasal karşılıklarını uygulayıcıların değer yargılarının belirleyecek olmasının getirdiği sübjektifliğin, söz konusu ilkelerin benimsenmesiyle bertaraf edilmesinin amaçlandığı anlaşılmaktadır. Anılan ilkelerin uygulamaya konulmasıyla, ulaşılacak ölçüm sonuçlarında güvence sağlanabilecektir.

\subsection{Etki Raporlama ve Yatırım Standartları (IRIS / Impact Reporting and Investment Standards)}

Küresel Etki Yatırımları Ağı, uygulamacılar için eğitim, sağlık, enerji ve finansal hizmetler gibi farklı sektörlere göre sınıflandırılmış sosyal etki göstergeleri seçebilmelerine imkan sağlayan bir katalog geliştirdi. Bu kataloğun amacı, etki yatırımları sektöründeki etki ölçüm uygulamalarında şeffaflık, güvenilirlik ve hesap verilebilirliği desteklemek olarak açıklanmıştır (IRIS, 2015). Nitel ve nicel ölçüm yöntemlerinin bir arada kullanıldığı IRIS kataloğunda finansal performans, operasyonel performans, ürün performansı, sektör performansı ve sosyal ve çevresel amaç performansı ayrı ayrı ölçülür. Ancak bunu yaparken bir derecelendirme ya da raporlama çerçevesi kullanılmaz. IRIS kataloğu, en iyi sektör uygulamalarını esas alarak bir karşılaştırma yapma imkanı sağlar.

IRIS, bir katalog biçiminde yapılandırıldığından, yatırımcılar için belirlenen hedeflere, farklı sektörlerin ihtiyaçlarına göre şekillendirilebilen bir ölçümleme yapabilmektedir. Bu ölçüm metodunda hem parasal hem de parasal olmayan ölçü birimleri kullanılmaktadır. IRIS; Uluslararası Çalışma Örgütü (ILO), Ekonomik Kalkınma ve İşbirliği Örgütü (OECD), Uluslararası Finansal Raporlama Standartları Kurulu gibi standart koyucu uluslararası örgütlerle işbirliği içinde olduğundan, anılan örgütlerin standartlarıyla bir arada uyumlu olarak kullanılabilecek şekilde tasarlanmıştır. Ayrıca değişimler ve yeni ihtiyaçlara göre güncellenmektedir (IRIS, 2015).

\subsection{Küresel Etki Yatırımı Derecelendirme Sistemi (GIIRS / Global Impact Investing Rating System)}

Bir derecelendirme sistemi olan GIIRS, B Lab tarafından ilk defa 2011'de geliştirildi. GIIRS, farklı etki alanlarında performans değerlendirmesi yaparak bir skor üretir. Öncesinde 'B etki değerlendirmesi' adı altında bir takım sorulara verilen cevaplara göre bir etki raporu üretilir. Etki değerlendirmesi, farklı sektörlerde faaliyet gösteren tüm kar amaçlı işletmeler için uygulanabilir. GIIRS, B etki değerlendirmesini kullanarak bir derecelendirme yapmaktadır.

GIIRS derecelendirme süreci üç aşamada ilerler: GIIRS değerlendirmesinin tamamlanması, doğrulama ve derecelendirme raporunun alınması. Herhangi bir işletme etki değerlendirmesini kendi kendine yaparak, çevrimiçi olarak hazırlanan etki raporunu kullanabilir, paydaşlarla paylaşabilir. Ancak geçerli ve onaylı bir GIIRS skoru alınabilmesi için değerlendirme sorularına verilen cevapların GIIRS yetkilileri tarafından gözden geçirilerek doğrulanması gerekir. GIIRS derecelendirmesi bir yıl için geçerlidir. Bu süre sonunda süreç yenilenir. B Lab, raporlama ve derecelendirmenin yanı sıra "B Analitik" olarak adlandırılan çevrimiçi platform üzerinden yatırımcılara her bir etki alanına ilişkin veri sağlamaktadır (B Lab, 2018; Social Value UK, 2016).

\subsection{Küresel Raporlama Girişimi (GRI / Global Reporting Initiative)}

Kar amacı gütmeyen, uluslararası bağımsız bir örgüt olarak 1997 yılında çevresel amaçlarla kurulan kuruluş, sürdürülebilirlik üzerine farklı sektörler ve işletmeler için kılavuzlar yayınlamıştır. 2016 yılında ise ilk defa Küresel Sürdürülebilirlik Raporlama Standartlarını yayınladı. GRI standartları, bir örgütün faaliyetlerinin sürdürülebilirlik bakımından değerlendirilmesini sağlayan bir metodolojidir. GRI raporlama standartları, yatııımların sürdürülebilirlik konuları üzerindeki etkisinin anlaşılması ve ilgililere iletilmesinde işletmelere, hükümetlere ve diğer örgütlere yardımcı olmak üzere hazırlandı (GRI, 2018).

GRI standartlarının konusu örgütlerin sürdürülebilirlik raporlamasıdır. Sürdürülebilirlik raporu, bir işletme ya da kuruluşun günlük faaliyetlerinin ekonomik, çevresel ve sosyal etkilerinin raporlanması anlamına gelip, kurumsal sosyal sorumluluk raporlaması, üçlü raporlama (triple bottom line reporting), bütünleşik raporlama (integrated reporting) gibi kavramlarla eşanlamlı ya da benzer anlamlıdır (GRI, 2018). GRI standartlarını esas alarak, pek çok kurum sürdürülebilirlik raporu hazırlamıştır ve hazırlamaya devam etmektedir.

\section{SONUC}

Özellikle Küresel Finansal Krizden sonra, getiri maksimizasyonu ve bireylerin servetinin artırımasını hedefleyen finans, pek çok eleştiriye uğramıştır. Bireysel faydadan ziyade, toplumsal etki, sürdürülebilirlik ve kurumsal yönetişimi önceleyen bir finansal anlayışın hem teorik alanda hem de uygulamada gelişmekte olduğu görülmektedir. Buna paralel olarak, farklı sosyal ihtiyaçlara hitap eden yeni yaklaşımların ve yeni ürünlerin tasarlanmasına, düzenlemelerin geliştirilmesine ve teşviklerin sağlanmasına ihtiyaç vardır. Bir paradigma değişiminden söz etmek, şimdilik aşırı iyimserlik olsa da tüm toplumun faydasını gözeten, çevre gibi konularda hassasiyet gösteren, sürdürülebilirliği dikkate alan bir finans ve yatırım modelinin gelişmesi, gelecek vadetmektedir. 


\section{KAYNAKLAR}

Addis, R. (2015). The roles of government policy in social finance. (Ed. A. Nicholls, R. Paton \& J. Emerson) Social Finance içinde, 383-459. Oxford: Oxford University Press.

Baker, H. K. \& Nofsinger, J. R. (2012). Socially Responsible Finance and Investing. New Jersey: Wiley.

B Lab. (2018). GIIRS. (Erişim tarihi: 18.10.2018) http://b-analytics.net/giirs-funds.

B Lab. (2018). About B-Corps. (Erişim tarihi: 15.10.2018) https://www.bcorporation.net/what-are-b-corps.

Bollen, N. P. B. (2007). Mutual fund attributes and investor behavior. Journal of Financial and Quantitative Analysis 42(3): 683-708.

Chiappini, H. (2017). Social Impact Funds: Definition, Assessment and Performance. Palgrave Studies in Impact Finance, Springer.

Commonfund Institute, (2013). From SRI to ESG: The changing world of responsible investing. (Erişim tarihi: 10.09.2018) http://info.commonfund.org/from-sri-to-esg-the-changing-world-of-responsible-investing.

Commonfund Institute, (2018). The challenges of terminology. (Erişim tarihi: 10.09.2018) https://www.commonfund.org/newsresearch/blog/what-are-the-differences-between-sri-and-esg/.

Drexler, M. \& Noble, A. (2013). From the margin to the mainstream: Assessment of the impact investment sector and opportunities to engage mainstream investors. Cologny: World Economic Forum.

http://www3.weforum.org/docs/WEF_II_FromMarginsMainstream_Report_2013.pdf.

Eurosif. (2016). European SRI study 2016. (Erişim tarihi: 10.09.2018) http://www.eurosif.org/wp-content/uploads/2016/11/SRI-study2016-HR.pdf.

Fullweiler, S. (2016). Sustainable finance. (Ed. O. M. Lehner) Routledge Handbook of Social and Sustainable Finance içinde, 17-34. New York: Routledge.

GIIN. (2018). What you need to know about impact investing. (Erişim tarihi: 10.09.2018) https://thegiin.org/impact-investing/need-toknow/.

GRI. (2018). The GRI standard. (Erişim tarihi: 18.10.2018) https://www.globalreporting.org/information/sustainability-reporting/Pages/gristandards.aspx.

Harji, K. \& Jackson, E.T. (2012). Accelerating impact: Achievements, challenges and what's next in building the impact investing industry. New York: The Rockefeller Foundation. (Erişim tarihi: 21.09.2018) https://assets.rockefellerfoundation.org/app/uploads/20120707215852/Accelerating-Impact-Full-Summary.pdf.

Höchstädter, A.K. \& Scheck, B. (2015). What's in a name: An analysis of impact investing understanding by academics and practitioners. Journal of Business Ethics 132(2): 449-475.

IRIS, (2015). Getting started with the IRIS. (Erişim tarihi: 18.10.2018) https://iris.thegiin.org/guide/getting-started-guide/summary.

Lehner, O.M. (2016). Crowdfunding social ventures. (Ed. O. M. Lehner) Routledge Handbook of Social and Sustainable Finance içinde, 139160. New York: Routledge.

O'Donohoe, N., Leijonjufvud, C., Saltuk, Y., Bugg-Levine, A. \& Brandenburg, M. (2010). Impact investment: An emerging asset class. New York: J.P. Morgan. (Erişim tarihi: 14.09.2018) http://www.compromisoytransparencia.org/upload/07/45/1. Impact Investments.pdf

Schinckus, C. (2018). The valuation of social impact bonds: An introductory perspective with the Peterborough SIB. Research in International Business and Finance, 45, 1-6.

SIIT. (2014a). Allocating for impact. (Erişim tarihi: 14.09.2018) http://gsgii.org/wp-content/uploads/2017/07/Asset-Allocation-WG-paper16.2.16-FINAL.pdf.

SIIT. (2014b). Impact investment: The invisible heart of markets. (Erişim tarihi: 14.09.2018) http://gsgii.org/wpcontent/uploads/2017/05/Impact-Investment-Report.pdf.

SIIT. (2014c). Measuring impact. (Erişim tarihi: 18.10.2018) https://iris.thegiin.org/research/measuring-impact-subject-paper-of-theimpact-measurement-working-group.pdf.

Social Value UK. (2016). GIIRS and SROI: What is the relationship? (Erişim tarihi: 18/10/2018)

http://www.socialvalueuk.org/app/uploads/2016/03/GIIRS\%20and\%20SROI\%20(2).pdf.

SROI Network. (2012). A Guide to social return on investment. (Erişim tarihi 18.09.2018)

http://www.socialvalueuk.org/app/uploads/2016/03/The\%20Guide\%20to\%20Social\%20Return\%20on\%20Investment\%202015.pdf.

UN PRI. (2016). Principles for Responsible Investment brochure. (Erişim tarihi 10.09.2018) https://www.unpri.org/download?ac=1534.

US SIF. (2016). The impact of sustainable and responsible investment. (Erişim tarihi 10.09. 2018)

https://www.ussif.org/files/Publications/USSIF_ImpactofSRI FINAL.pdf. 
US SIF. (2017). 2017 Annual report: US SIF and US SIF Foundation. (Erişim tarihi 10.09. 2018)

https://www.ussif.org/files/Publications/2017USSIFAnnualReport_online.pdf.

Weber, O. \& Duan, Y., (2012). Social Finance and Banking. Baker \& Nofsinger. (Ed.) Socially Responsible Finance and Investing içinde, 161180. New Jersey: Wiley.

Wilson, K. E., Silva, F., \& Ricardson, D. (2015). Social Impact Investment: Building the Evidence Base. Paris: OECD Publications. https://ssrn.com/abstract=2562082. 